\title{
Lightning strikes as a major source of prebiotic reduced phosphorus on early Earth
}

\author{
BENJAMIN HESS ${ }^{1,2,3}$, SANDRA PIAZOLO ${ }^{2}$ AND JASON \\ HARVEY ${ }^{2}$ \\ ${ }^{1}$ Yale University \\ ${ }^{2}$ University of Leeds \\ ${ }^{3}$ Wheaton College \\ Presenting Author: benjamin.hess@yale.edu
}

Phosphorus is one of the essential elements for the origin of life. However, while phosphorus is nearly ubiquitous on Earth's surface, it is locked in largely unreactive phosphate minerals such as apatite. In contrast, phosphides such as schreibersite, $(\mathrm{Fe}, \mathrm{Ni})_{3} \mathrm{P}$, an accessory minerals in meteorites, are highly reactive. Past workers have demonstrated that hydrated schreibersite forms activated phosphate which can react to create important biomolecules such as nucleosides [1]. Recent work shows that even the intermediate phosphite and hypophosphite species generated from hydrated schreibersite can efficiently form activated orthophosphate [2]. Consequently, meteoritesourced schreibersite is a popular proposed mechanism for prebiotic reactive phosphorus.

In our work, we identify an alternate source for widespread reduced phosphorus production: lightning strikes. We have identified abundant schreibersite spherules in a fulgurite, or, glass created by a lightning strike. Combining our findings with a previous study which documents the formation of phosphite and hypophosphite in fulgurites [3], we estimate that lightning strikes on early Earth potentially formed $10-1,000 \mathrm{~kg}$ of terrestrial phosphide and 100-10,000 $\mathrm{kg}$ of terrestrial phosphite and hypophosphite annually. As meteorite flux decreases monotonically, we estimate that the amount of phosphorus reduced by lightning strikes rivals the amount of terrestrial reduced phosphorus sourced from meteorites in the early Archean, exceeding the meteorite source by $3.5 \mathrm{Ga}$. Further, we estimate that on idealized tropical basaltic islands, local production of reduced phosphorus from lightning strikes could form tens to a few hundred grams of reduced phosphorus per year per $\mathrm{km}^{2}$. The concentration would increase through time as phosphorus weathers out slowly and new fulgurites form. Therefore, lightning strikes were likely a significant, widespread facilitator of phosphorus reduction on early Earth which may have played a role in the origin of life on Earth. Additionally, lightning strikes provides a widespread mechanism of phosphorus reduction independent of meteorites which may operate on other Earth-like planets, potentially indefinitely prolonging the window for the emergence of life.

[1] Gull et al. (2015), Scientific Reports, 5, 17198.

[2] Ritson, Mojzsis \& Sutherland (2020), Nature Geoscience, 13, 344-348.

[3] Pasek \& Block (2009), Nature Geoscience, 2, 553-556. 